\title{
Structure elucidation and photochemistry of substituted carboxylic compounds by low temperature matrix-isolation and solid state vibrational spectroscopy
}

\author{
Rui Fausto ${ }^{a, *}$, Ermelinda M.S. Maçôas ${ }^{a}$, A. Kulbida ${ }^{\mathrm{b}}$ \\ ${ }^{a}$ Departmento de Química, Universidade de Coimbra, P-3049 Coimbra, Portugal \\ ${ }^{\mathrm{b}}$ Institute of Physics, St. Petersburg University, Peterhof, 198904 St. Petersburg, Russia
}

Received 24 August 1998; accepted 30 September 1998

\begin{abstract}
Molecular structures and chemical reactivity (aggregation, phase transitions and photochemistry) of a series of substituted carboxylic acids were studied by low temperature matrix isolation and solid state vibrational spectroscopy, complemented by ab initio molecular orbital calculations. The conformational preferences exhibited by the isolated molecules of the systems under study are analyzed, and the effects of aggregation, temperature change and irradiation are discussed. () 1999 Elsevier Science B.V. All rights reserved.
\end{abstract}

Keywords: Matrix isolation spectroscopy; Solid state spectroscopy; Carboxylic acids; Aggregation; Photochemical reactivity

\section{Introduction}

Vibrational spectroscopy can be considered as one of the most powerful methods to study intermolecular interactions. On one hand, it can be used as a structure probe, as vibrational spectra are strongly determined by chemical environment, and more or less straightforward relationships can be established between the spectral parameters and molecular structure. On the other hand, most of the times vibrational spectroscopy can also provide relevant dynamical information, that can be used to understand the physical (or chemical) processes that are on the basis of intermolecular interactions.

Time-resolved vibrational spectroscopy is a

\footnotetext{
* Corresponding author. Tel.: + 351-39-852080; fax: + 35139-827703.

E-mail address: rfausto@gemini.ci.uc.pt (R. Fausto)
}

particularly powerful method for the study of phenomena such as aggregation, phase transitions, or chemical reactivity in general [1,2]. However, despite the recent developments in this field, there is still an understandable appeal in alternative methods, based on more conventional techniques. The most important and powerful of such methods is matrix isolation spectroscopy (MIS), whereby the species to be studied are preserved at extremely low temperatures (some degrees Kelvin) in an inert solid matrix, usually made from a noble gas. Under these conditions, species that are normally short lived can be preserved indefinitely and investigated at leisure $[3,4]$. In addition, this method has the very convenient property of yielding results that can be easily compared with those obtained from standard theoretical calculations (quantum chemical or molecular mechanics) where the molecular systems under study 
are usually considered to be isolated in vacuum or placed in an isotropic homogeneous environment [5-7].

As the working temperature in a typical MIS experiment is very low and the host matrix shows an appreciable chemical inertia, the perturbations suffered by the trapped species resulting from matrix-substrate interactions are minimized (typically the differences between the vibrational frequencies obtained for a molecule in the gaseous phase and isolated in a noble gas matrix are less than $1 \%$ ). In addition, the rigidity of the solid matrix inhibits rotational transitions. Together, these effects lead to a strong increase in spectral resolution, which may easily attain values greater than $0.01 \mathrm{~cm}^{-1}$. Such an increase in resolution is of great utility in conformational analysis, as in general conformers give rise to vibrational bands that do not differ largely in frequency. In contrast, when the relative energies of the various species participating in a given equilibrium are very close (and this is usually the situation for conformational equilibria), a temperature change in the high temperature region (or even in the moderately low temperature domain) does not give rise to a significant modification of their relative populations. Thus, under usual conditions, the spectroscopic identification of these species becomes extremely difficult, or even impossible in practical terms. However, at the very low temperatures typical of the matrix isolation experiments, a small variation of the temperature leads to very important changes in the relative populations of the various forms, enabling their easy identification and spectroscopic characterization, as well as the determination of the relevant thermodynamic properties associated with the corresponding equilibrium.

MIS has also been particularly very successful for studying photochemical reactivity, taking advantage of the very low work temperature - that minimizes the available thermal energy, reducing the probability of the occurrence of thermal reactions of dissociation or rearrangements - as well as from the usual very low concentration of the trapped species and relative rigidity of the matrix cage, that inhibit diffusion and minimize the chance of encounters between the particles. The effect of the temperature, in particular, is remarkable: it is easy to calculate that the ratio between the rate constants at room temperature
$(298 \mathrm{~K})$ and at $10 \mathrm{~K}$, of a chemical reaction having an activation energy of $5 \mathrm{~kJ} \mathrm{~mol}^{-1}$, is $10^{25}$. As is relatively easy to start photochemical reactions in a matrix by irradiation of the sample at specific wavelengths, this technique has unique advantages both for identification and characterization of photochemical reactions (in particular photodegradations and rearrangement reactions) and for the study of photochemically induced conformational isomerization reactions.

Together with solid state vibrational spectroscopic studies undertaken on pure substances, MIS can provide detailed information on vibrational signature of monomeric species and aggregates of different sizes and on the intermolecular interactions that are operating in these later, in particular, hydrogen bonding $[7,8]$.

In this article, a series of structural and photochemical studies on a variety of carboxylic compounds, carried out by a combined MIS, solid state vibrational spectroscopy and quantum chemical calculations, are reported. The conformational preferences exhibited by the isolated molecules of the systems under study are analyzed, and the effects of aggregation, temperature change and irradiation are discussed. Firstly, IR induced conformational isomerization of chloroacetic acid monomer $\left(\mathrm{CH}_{2} \mathrm{ClCOOH}\right)$ is discussed, and a mechanism for intramolecular vibrational energy transfer presented. Secondly, crotonic acid $\mathrm{CH}_{3} \mathrm{CH}=\mathrm{CHCOOH} \mathrm{UV}$ induced isomerization and photodecomposition are analyzed, and the main intermolecular interactions that are operating in the crystalline phase of this compound evaluated. Finally, the structures of the different crystalline varieties of malonic acid $\left(\mathrm{CH}_{2}(\mathrm{COOH})_{2}\right)$ are elucidated and spectroscopically characterized.

\section{Experimental}

All samples were obtained commercially spectroscopic grade and purified by standard methods prior to spectra recording. Argon of $99.999 \%$ purity was obtained from Messer Griesheim $\mathrm{GmbH}$. The matrices were prepared in a conventional way by deposition of the gaseous mixture on a gold plated copper mirror, cooled using a ROK 10-300 (Leybold-Heraeus) closed-cycle refrigerator. The 
deposition temperatures, measured at the mirror, were 13 or $18 \mathrm{~K}$, the matrix: solute ratios were ca. 1500 and the rates of the matrix gas flow ca. 5.0 $\times$ $10^{-3} \mathrm{~mol} \mathrm{~h}^{-1}$. The MIS IR spectra were obtained in reflection mode $\left(0.5 \mathrm{~cm}^{-1}\right.$ resolution) on a Bruker IFS $66 \mathrm{~V}$ Fourier transform spectrometer equipped with a germanium/CsI beam splitter and with a deuterated triglycine sulfide (DTGS) detector fitted with CsI windows. The irradiation of the samples was carried out by using a UV light source whose main component is a $500 \mathrm{~W}$ Xe arc lamp or by means of a CO laser (for IR irradiation). Solid state IR spectra were obtained for samples as $\mathrm{KBr}$ pellets using a Nicolet 800 or Mattson Infinity Series Fourier transform spectrometer, equipped with a germanium/CsI beam splitter and with a DTGS detector fitted with CsI windows, with $1 \mathrm{~cm}^{-1}$ spectral resolution. Raman spectra were obtained using a SPEX 1403 double monochromator spectrometer (focal distance $0.85 \mathrm{~m}$, aperture f/7.8), with holographic gratings with 1800 grooves $\mathrm{mm}^{-1}$ (ref. 1800-1SHD). The $514.5 \mathrm{~nm}$ argon laser (Spectra-Physics, model 164$05)$ line, adjusted to provide $220 \mathrm{~mW}$ at the sample, was used as excitation radiation. Detection was effected using a thermoelectrically cooled Hamamatsu R928 photomultiplier. Spectra were recorded using increments of $1 \mathrm{~cm}^{-1}$ and integration times of $1 \mathrm{~s}$. Under these conditions, the estimated errors in wavenumbers are $\pm 1 \mathrm{~cm}^{-1}$.

The molecular orbital calculations were performed both at the ab initio 6-31G* [9] and semiempirical (AM1 [10]) levels of theory, using the GAUSSIAN 92 program package [11] running on a DEC ALPHA 7000 computer. Molecular geometries were fully optimized by the force gradient method using Berny's algorithm [12]. The largest residual coordinate forces were always less than $3 \times 10^{-4}$ hartree bohr ${ }^{-1}$ $\left(1\right.$ hartree $=2625.5001 \mathrm{~kJ} \mathrm{~mol}^{-1} ; 1 \mathrm{bohr}=$ $\left.5.29177 \times 10^{-11} \mathrm{~m}\right)$ or hartree $\mathrm{rad}^{-1}$, for bond stretches and angle bends, respectively. The $6-31 \mathrm{G}^{*}$ $\mathrm{ab}$ initio calculated wavenumbers were scaled down in order to fit to the experimental values by using a single linear equation for each symmetry species, while AM1 calculated values for each individual vibration were corrected by means of a simple additive term (the correction terms were determined for the monomeric species and then used to predict the vibrational wavenumbers of dimeric structures).
Normal coordinate analyses were undertaken using the programs TRANSFORMER, BUILD-G and VIBRAT [13,14], which are interfaced with the GAUSSIAN 92 program.

\section{Results and discussion}

\subsection{Conformational isomerism and intramolecular vibrational energy transfer in $\mathrm{CH}_{2} \mathrm{ClCOOH}$}

Three conformers of choroacetic acid monomer have been experimentally observed by electron diffraction and microwave spectroscopy in the midseventies $[15,16]$ and, more recently, by matrix isolation infrared spectroscopy [8]. The most stable form was found to be the syn/s-cis conformer (SC), where the chlorine and carbonyl oxygen atoms are eclipsed and the $\mathrm{O}=\mathrm{C}-\mathrm{O}-\mathrm{H}$ dihedral angle is $0^{\circ}$ (Fig. 1(a)). The second more stable conformer was found to have $\mathrm{C}_{1}$ symmetry, and corresponds to the doubly degenerated by symmetry skew/s-cis form (SKC; Fig. 1(b)), which does not differ very much in energy from the $\mathrm{SC}$ form $\left(\Delta E_{\mathrm{SKC}-\mathrm{SC}}: 4.85 \mathrm{~kJ} \mathrm{~mol}^{-1}\right.$, exp. electron diffraction [16]; $2.52 \mathrm{~kJ} \mathrm{~mol}^{-1}$, calc. ab initio MP2/ 6-31G*). The less stable conformer experimentally observed has a considerably higher energy than the two $s$-cis conformers and corresponds to the anti/strans form (AT; $\Delta E_{\mathrm{AT}-\mathrm{SC}}: 16.09 \mathrm{~kJ} \mathrm{~mol}^{-1}$, calc. ab initio MP2/6-31G*), showing and intramolecular

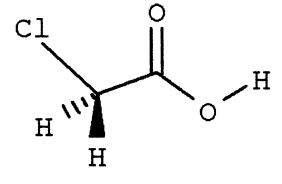

(a) SC

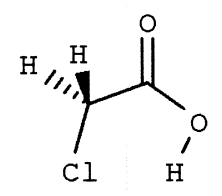

(c) AT<smiles>[CH2]C(=O)CO</smiles>

(b) SKC

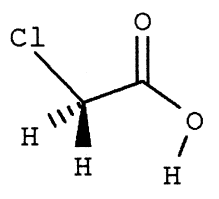

(d) $\mathrm{ST}$
Fig. 1. Conformers of chloroacetic acid (monomer). 
(a)

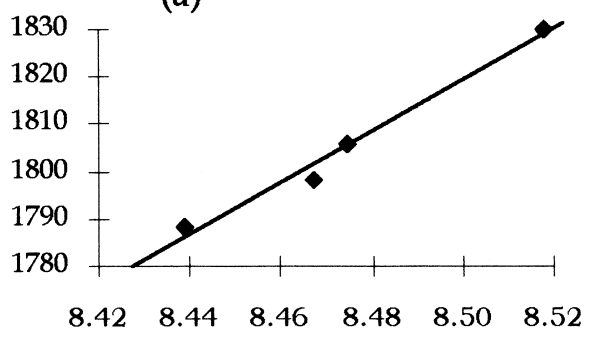

$1 / \mathrm{r}(\mathrm{C}=\mathrm{O}) \times 1000$

(b)

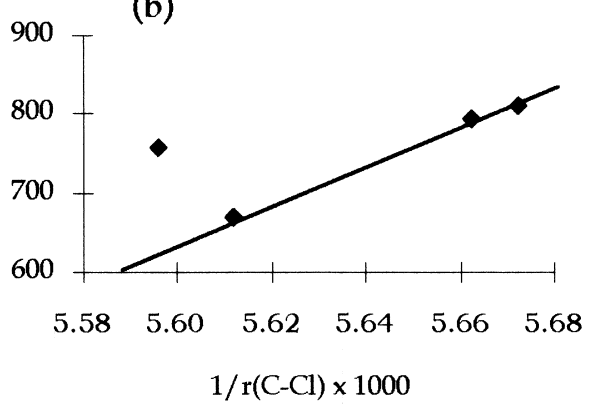

Fig. 2. Correlation of (a) $\nu(\mathrm{C}-\mathrm{O})$ with $1 / r_{(\mathrm{C}=0)}$ and (b) $\nu(\mathrm{C}-\mathrm{Cl})$ with $1 / r_{(\mathrm{C}-\mathrm{Cl})}$. The point that does not fit in the straight line in (b) corresponds to the AT form. This apparent anomaly is in consonance with the occurrence of a hydrogen bond involving the chlorine atom, as suggested in the text.

$\mathrm{OH} . . \mathrm{Cl}$ hydrogen bond (Fig. 1(c)) [8]. Besides these three conformers, it has been suggested that an additional high energy conformer (ST; Fig. 1(d)) also exists, despite the fact it has never been found experimentally [17]. The MP2/6-31G* predicted energy difference between this conformer and the most stable form amount to $32.70 \mathrm{~kJ} \mathrm{~mol}^{-1}$.

By comparing the $6.31 \mathrm{G}^{*}$ calculated geometries of the various conformers, it can be concluded that the main intramolecular interactions which determine their relative stability are $\mathrm{H} \ldots \mathrm{H}(\mathrm{O})$ and $\mathrm{C} 1 \ldots \mathrm{O}$ (both $\mathrm{O}=$ and $-\mathrm{O}-$ ) repulsive interactions (steric or coulombic), and the mesomerism within the carboxylic group, $\mathrm{CH}_{2} \mathrm{ClC}(=\mathrm{O})-\mathrm{OH} \leftrightarrow \mathrm{CH}_{2} \mathrm{ClC}$ $\left(-\mathrm{O}^{-}\right)=\mathrm{O}^{+} \mathrm{H}$. The high energy of the ST conformer is mainly determined by the $\mathrm{H} \ldots \mathrm{H}(\mathrm{O})$ interactions, while the balance between the $\mathrm{C} 1 \ldots \mathrm{O}$ repulsions (Cl...-O- interactions were found to be stronger than $\mathrm{Cl} \ldots \mathrm{O}=$ repulsions, as usually [17]) and the mesomerism within the $\mathrm{C}(=\mathrm{O}) \mathrm{O}$ group (which is less important for a $\mathrm{Cl} \ldots \mathrm{O}=$ eclipsed geometry) determines the relative stability of the two s-cis conformers (SC,SKS), leading to a more stable SC form. The AT conformer has a staggered arrangement of the $\mathrm{CH}_{2} \mathrm{Cl}$ group relatively to the carbonyl moiety that leads to unfavorable group orbital interactions [18]. However, the energy of this conformer is relatively close to those of the two s-cis conformers (and much lower than that of the ST form), as it is stabilized by the presence of the $\mathrm{OH} . . . \mathrm{Cl}$ intramolecular hydrogen bond.

Forms $\mathrm{SC}$, AT and ST belong to the $\mathrm{C}_{\mathrm{s}}$ point group and their 18 normal modes span the irreducible representations, $12 \mathrm{~A}^{\prime}+6 \mathrm{~A}^{\prime}$. Form SKC is nonsymmetric $\left(C_{1}\right.$ point group). In all cases all vibrations are predicted to be IR active. Table 1 shows the experimental (MIS; Ar matrix; $13 \mathrm{~K}$ ) and calculated infrared frequencies and calculated potential energy distributions (PED) for the various studied conformers.

It is interesting to note that the frequencies of both $\nu(\mathrm{C}-\mathrm{Cl})$ and $\nu(\mathrm{C}=\mathrm{O})$ stretching vibrations correlate well with the inverse of the corresponding bond lengths (Fig. 2). In particular, the two syn forms (SC and ST) which possess the shortest bond lengths originate the highest frequencies. These are direct results of the reduced polarizations of the $\mathrm{C}-\mathrm{Cl}$ and $\mathrm{C}=\mathrm{O}$ bonds caused by the parallel alignment of the $\mathrm{C}-\mathrm{C} 1$ and $\mathrm{C}=\mathrm{O}$ bond dipole moments in these conformers. The point in Fig. 2(b) that does not fit in the straight line corresponds to the AT conformer. This apparent anomaly is in consonance with the participation of the chlorine atom in the $\mathrm{OH} . . \mathrm{C} 1$ intramolecular hydrogen bond which is predicted to occur in this conformer.

When the matrix-isolated chloroacetic acid is submitted to irradiation in the $\nu(\mathrm{C}=\mathrm{O})$ region with the $1805 \mathrm{~cm}^{-1} \mathrm{CO}$ laser line, rotamerization reactions are observed: (a) Irradiation of the deposited sample leads to both $\mathrm{SC} \rightarrow \mathrm{SKC}$ and $\mathrm{SC} \rightarrow \mathrm{AT}$ rotamerizations. (b) Irradiation during sample deposition leads mainly to $\mathrm{SC} \rightarrow \mathrm{SKC}$ conversion. (c) Irradiation of the annealed sample, i.e., after the $\mathrm{SC} \rightarrow \mathrm{SKC}$ and $\mathrm{SC} \rightarrow$ AT rotamerizations take place, does not produce any change. No evidence was found for the $\mathrm{SC} \rightarrow \mathrm{ST}$ rotamerization. 
Table 1

Experimental and calculated wave numbers $\left(\nu / \mathrm{cm}^{-1}\right)$ and PED $(\%)$ for chloroacetic acid (monomers) ( $\nu$, stretching; $\delta$, bending; $\omega$, wagging; t, twisting; $\gamma$, rocking; $\tau$, torsion; n.o., not observed. Symmetry of each mode applies only to $\mathrm{C}_{\mathrm{s}}$ conformers (SC, AT, ST). Wavenumbers presented are ab initio 6-31G* (scaled) calculated values; $\Delta \nu=\nu_{\text {calc }}-\nu_{\text {exp }}$ )

\begin{tabular}{|c|c|c|c|c|c|c|c|}
\hline & & \multicolumn{3}{|l|}{$\mathrm{SC}$} & \multicolumn{3}{|l|}{ SKC } \\
\hline & & $\nu$ & $\Delta \nu$ & PED & $\nu$ & $\Delta \nu$ & PED \\
\hline$\nu \mathrm{O}-\mathrm{H}$ & $\mathrm{a}^{\prime}$ & 3570 & {$[0]$} & & 3574 & {$[17]$} & \\
\hline$\nu \mathrm{CH}_{2}$ & $a^{\prime \prime}$ & 3034 & n.o. & & 3070 & n.o. & \\
\hline$\nu \mathrm{CH}_{2}$ & $\mathrm{a}^{\prime}$ & 2980 & n.o. & & 2993 & n.o. & \\
\hline$\nu \mathrm{C}=\mathrm{O}$ & $a^{\prime}$ & 1806 & {$[0]$} & & 1788 & [13] & \\
\hline$\delta \mathrm{CH}_{2}$ & a & 1429 & [1] & & 1425 & {$[0]$} & \\
\hline$\delta \mathrm{COH}$ & $a^{\prime}$ & 1352 & {$[-2]$} & $\begin{array}{l}\delta \mathrm{COH}\{10\}+\omega \mathrm{CH}_{2}\{38\}+ \\
\nu \mathrm{C}-\mathrm{O}\{20\}\end{array}$ & 1220 & {$[-10]$} & $\begin{array}{l}\delta \mathrm{COH}\{51\}+\mathrm{tCH}_{2}\{25\}+ \\
\nu \mathrm{C}-\mathrm{O}\{15\}\end{array}$ \\
\hline$\omega \mathrm{CH}_{2}$ & $\mathrm{a}^{\prime}$ & 1278 & {$[0]$} & $\omega \mathrm{CH}_{2}[46]+\delta \mathrm{COH}\{41\}$ & 1278 & [9] & \\
\hline $\mathrm{tCH}_{2}$ & $a^{\prime \prime}$ & 1196 & {$[1]$} & & 1130 & {$[-7]$} & $\begin{array}{l}\mathrm{tCH}_{2}\{66\}+\nu \mathrm{C}-\mathrm{O}\{20\}+ \\
\delta \mathrm{COH}\{14\}\end{array}$ \\
\hline$\nu \mathrm{C}-\mathrm{O}$ & $a^{\prime}$ & 1112 & [1] & $\begin{array}{l}\nu \mathrm{C}-\mathrm{O}\{58\}+\nu \mathrm{C}-\mathrm{O}\{34\}+ \\
\omega \mathrm{CH}_{2}\{16\}\end{array}$ & 1360 & {$[-6]$} & $\begin{array}{l}\nu \mathrm{C}-\mathrm{O}\{34\}+\nu \mathrm{C}-\mathrm{C}\{20\}+ \\
\delta \mathrm{COH}\{17\}+\delta \mathrm{O}=\mathrm{CO}\{16\}\end{array}$ \\
\hline$\gamma \mathrm{CH}_{2}$ & $a^{\prime \prime}$ & 929 & {$[0]$} & $\gamma \mathrm{CH}_{2}\{62\}+\gamma \mathrm{C}=\mathrm{O}\{29\}$ & 927 & n.o. & $\gamma \mathrm{CH}_{2}\{72\}+\delta \mathrm{CC}=\mathrm{O}\{12\}$ \\
\hline$\nu \mathrm{C}-\mathrm{C}$ & $a^{\prime}$ & 894 & [2] & $\begin{array}{l}\nu \mathrm{C}-\mathrm{C}\{49\}+\nu \mathrm{C}-\mathrm{Cl}\{24\}+ \\
\nu \mathrm{C}-\mathrm{O}\{12\}\end{array}$ & 860 & n.o. & $\nu \mathrm{C}-\mathrm{C}\{48\}+\nu \mathrm{C}-\mathrm{O}\{26\}$ \\
\hline$\nu \mathrm{C}-\mathrm{Cl}$ & $a^{\prime}$ & 794 & {$[1]$} & $\begin{array}{l}\nu \mathrm{C}-\mathrm{Cl}\{55\}+\delta \mathrm{CC}- \\
\mathrm{Cl}\{20\}+\delta \mathrm{CC}=\mathrm{O}\{18\}+ \\
\nu \mathrm{C}-\mathrm{C}\{12\}\end{array}$ & 668 & [17] & $\begin{array}{l}\nu \mathrm{C}-\mathrm{Cl}\{38\}+\mathrm{tC}-\mathrm{O}\{35\}+ \\
\delta \mathrm{O}=\mathrm{CO}\{17\}+\gamma \mathrm{C}=\mathrm{O}\{20\}\end{array}$ \\
\hline$\tau \mathrm{C}-\mathrm{O}$ & $a^{\prime \prime}$ & 613 & [2] & $\begin{array}{l}\tau \mathrm{C}-\mathrm{O}\{89\}+\gamma \mathrm{C}=\mathrm{O}\{35\}+ \\
\gamma \mathrm{CH}_{2}\{15\}\end{array}$ & 511 & [2] & $\begin{array}{l}\tau \mathrm{C}-\mathrm{O}\{16\}+\gamma \mathrm{C}=\mathrm{O}\{22\}+ \\
\delta \mathrm{O}=\mathrm{CO}\{21\}+\nu \mathrm{C}-\mathrm{Cl}\{17\}\end{array}$ \\
\hline$\delta \mathrm{O}=\mathrm{CO}$ & $\mathrm{a}^{\prime}$ & 606 & [1] & & 570 & {$[-15]$} & $\delta \mathrm{O}=\mathrm{CO}\{42\}+\tau \mathrm{C}-\mathrm{O}\{46\}$ \\
\hline$\gamma \mathrm{C}=\mathrm{O}$ & $a^{\prime \prime}$ & 489 & {$[-3]$} & $\begin{array}{l}\gamma \mathrm{C}=\mathrm{O}\{68\}+\gamma \mathrm{CH}_{2}\{26\}+ \\
\tau \mathrm{C}-\mathrm{O}\{16\}\end{array}$ & 827 & n.o. & $\begin{array}{l}\gamma \mathrm{C}=\mathrm{O}\{44\}+\nu \mathrm{C}-\mathrm{Cl}\{43\}+ \\
\delta \mathrm{CCCl}\{15\}\end{array}$ \\
\hline$\delta \mathrm{CC}=\mathrm{O}$ & $a^{\prime}$ & 384 & [5] & $\begin{array}{l}\delta \mathrm{CC}=\mathrm{O}\{37\}+\nu \mathrm{C}- \\
\mathrm{C}\{24\}+\delta \mathrm{O}=\mathrm{CO}\{13\}\end{array}$ & 379 & n.o. & $\delta \mathrm{CC}=\mathrm{O}\{84\}+\gamma \mathrm{CH}_{2}\{15\}$ \\
\hline$\delta \mathrm{CCCl}$ & $a^{\prime}$ & 220 & {$[-4]$} & $\delta \mathrm{CCCl}\{66\}+\delta \mathrm{CC}=\mathrm{O}\{34\}$ & 217 & n.o. & $\begin{array}{l}\delta \mathrm{CCCl}\{71\}+\gamma \mathrm{C}=\mathrm{O}\{16\}+ \\
\delta \mathrm{CC}=\mathrm{O}\{10\}\end{array}$ \\
\hline \multirow[t]{3}{*}{$\tau \mathrm{C}-\mathrm{C}$} & $a^{\prime \prime}$ & 62 & {$[0]$} & $\tau \mathrm{C}-\mathrm{C}\{88\}+\gamma \mathrm{C}=\mathrm{O}\{12\}$ & 48 & n.o. & $\tau \mathrm{C}-\mathrm{C}\{66\}+\delta \mathrm{CCl}\{19\}$ \\
\hline & & \multicolumn{3}{|l|}{ AT } & \multicolumn{3}{|l|}{ ST } \\
\hline & & $\nu$ & $\Delta \nu$ & PED & $\nu$ & & PED \\
\hline$\nu \mathrm{O}-\mathrm{H}$ & $a^{\prime}$ & 3596 & [90] & & 3612 & & \\
\hline$\nu \mathrm{CH}_{2}$ & $a^{\prime \prime}$ & 3061 & n.o. & & 3006 & & \\
\hline$\nu \mathrm{CH}_{2}$ & $\mathrm{a}^{\prime}$ & 3000 & n.o. & & 2954 & & \\
\hline$\nu \mathrm{C}=\mathrm{O}$ & $\mathrm{a}^{\prime}$ & 1798 & [8] & & 1830 & & \\
\hline$\delta \mathrm{CH}_{2}$ & $a^{\prime}$ & 1400 & n.o. & & 1419 & & \\
\hline$\delta \mathrm{COH}$ & $a^{\prime}$ & 1192 & n.o. & $\begin{array}{l}\delta \mathrm{COH}\{52\}+\nu \mathrm{C}-\mathrm{O}\{25\}+ \\
\nu \mathrm{C}-\mathrm{C}\{12\}\end{array}$ & 1269 & & $\begin{array}{l}\delta \mathrm{COH}\{56\}+\omega \mathrm{CH}_{2}\{28\}+ \\
\nu \mathrm{C}-\mathrm{O}\{16\}\end{array}$ \\
\hline$\omega \mathrm{CH}_{2}$ & $a^{\prime}$ & 1278 & {$[-10]$} & & 1344 & & $\begin{array}{l}\omega \mathrm{CH}_{2}\{63\}+\nu \mathrm{C}-\mathrm{O}\{20\}+ \\
\nu \mathrm{C}-\mathrm{C}\{17\}\end{array}$ \\
\hline $\mathrm{tCH}_{2}$ & $a^{\prime \prime}$ & 1191 & n.o. & & 1200 & & \\
\hline$\nu \mathrm{C}-\mathrm{O}$ & $a^{\prime}$ & 1348 & {$[14]$} & $\begin{array}{l}\nu \mathrm{C}-\mathrm{O}\{47\}+\delta \mathrm{COH}\{40\}+ \\
\nu \mathrm{C}-\mathrm{C}\{19\}+\delta \mathrm{O}=\mathrm{CO}\{13\}\end{array}$ & 1092 & & $\begin{array}{l}\nu \mathrm{C}-\mathrm{O}\{46\}+\delta \mathrm{COH}\{28\}+ \\
\omega \mathrm{CH}_{2}\{12\}\end{array}$ \\
\hline$\gamma \mathrm{CH}_{2}$ & $a^{\prime \prime}$ & 920 & n.o. & $\gamma \mathrm{CH}_{2}\{64\}+\gamma \mathrm{C}=\mathrm{O}\{19\}$ & 933 & & $\gamma \mathrm{CH}_{2}\{63\}+\gamma \mathrm{C}=\mathrm{O}\{25\}$ \\
\hline$\nu \mathrm{C}-\mathrm{C}$ & $a^{\prime}$ & 862 & [10] & $\begin{array}{l}\nu \mathrm{C}-\mathrm{C}\{50\}+\nu \mathrm{C}-\mathrm{Cl}\{14\}+ \\
\nu \mathrm{C}-\mathrm{O}\{24\}\end{array}$ & 889 & & $\begin{array}{l}\nu \mathrm{C}-\mathrm{C}\{49\}+\nu \mathrm{C}-\mathrm{Cl}\{23\}+ \\
\nu \mathrm{C}-\mathrm{O}\{14\}\end{array}$ \\
\hline
\end{tabular}


Table 1 (continued)

\begin{tabular}{|c|c|c|c|c|c|c|}
\hline & & \multicolumn{3}{|l|}{ AT } & \multicolumn{2}{|l|}{$\mathrm{ST}$} \\
\hline & & $\nu$ & $\Delta \nu$ & PED & $\nu$ & PED \\
\hline$\nu \mathrm{C}-\mathrm{Cl}$ & $\mathrm{a}^{\prime}$ & 758 & {$[-13]$} & $\begin{array}{l}\nu \mathrm{C}-\mathrm{Cl}\{64\}+\delta \mathrm{CC}- \\
\mathrm{Cl}\{19\}+\delta \mathrm{CC}=\mathrm{O}\{25\}\end{array}$ & 810 & $\begin{array}{l}\nu \mathrm{C}-\mathrm{Cl}\{54\}+\delta \mathrm{CC}- \\
\mathrm{Cl}\{17\}+\delta \mathrm{CC}=\mathrm{O}\{17\}+ \\
\nu \mathrm{C}-\mathrm{C}\{13\}\end{array}$ \\
\hline$\tau \mathrm{C}-\mathrm{O}$ & $a^{\prime \prime}$ & 452 & n.o. & & 366 & $\tau \mathrm{C}-\mathrm{O}\{85\}+\gamma \mathrm{C}=\mathrm{O}\{23\}$ \\
\hline$\delta \mathrm{O}=\mathrm{CO}$ & $\mathrm{a}^{\prime}$ & 610 & {$[14]$} & $\delta \mathrm{O}=\mathrm{CO}\{73\}+\delta \mathrm{CCCl}\{14\}$ & 625 & \\
\hline$\gamma \mathrm{C}=\mathrm{O}$ & $a^{\prime \prime}$ & 573 & [47] & $\gamma \mathrm{C}=\mathrm{O}\{58\}+\gamma \mathrm{CH}_{2}\{34\}$ & 567 & $\begin{array}{l}\gamma \mathrm{C}=\mathrm{O}\{76\}+\gamma \mathrm{CH}_{2}\{38\}+ \\
\tau \mathrm{C}-\mathrm{O}\{14\}\end{array}$ \\
\hline$\delta \mathrm{CC}=\mathrm{O}$ & $\mathrm{a}^{\prime}$ & 400 & n.o. & $\delta \mathrm{CC}=\mathrm{O}\{48\}+\nu \mathrm{C}-\mathrm{Cl}\{31\}$ & 384 & $\begin{array}{l}\delta \mathrm{CC}=\mathrm{O}\{36\}+\nu \mathrm{C}- \\
\mathrm{Cl}\{25\}+\delta \mathrm{O}=\mathrm{CO}\{12\}\end{array}$ \\
\hline$\delta \mathrm{CCCl}$ & $\mathrm{a}^{\prime}$ & 249 & n.o. & $\delta \mathrm{CCCl}\{64\}+\delta \mathrm{CC}=\mathrm{O}\{20\}$ & 223 & $\delta \mathrm{CCCl}\{68\}+\delta \mathrm{CC}=\mathrm{O}\{32\}$ \\
\hline$\tau \mathrm{C}-\mathrm{C}$ & $a^{\prime \prime}$ & 33 & n.o. & & 72 & $\tau \mathrm{C}-\mathrm{C}\{88\}+\gamma \mathrm{C}=\mathrm{O}\{12\}$ \\
\hline
\end{tabular}

Hence, by irradiation in the $\nu(\mathrm{C}=\mathrm{O})$ region, only the $\mathrm{SC}$ form converts to other forms. In contrast, restricted free volume conditions make the $\mathrm{SC} \rightarrow$ AT rotamerization more important, while in less restricted-free-volume situations (e.g., during sample deposition) the SC $\rightarrow$ SKC rotamerization dominates. Unlike the non-symmetric SKC conformer, the AT form can be embedded in the primarily occupied volume, and this justifies the relative increase of importance of the $\mathrm{SC} \rightarrow \mathrm{AT}$ conversion process upon restricted-free-volume conditions. In the absence of significant volume restrictions, the $\mathrm{SC} \rightarrow$ $\mathrm{SKC}$ rotamerization process clearly dominates as it is strongly favored in energetic terms.

The mechanism of intramolecular vibrational energy redistribution leading to the photochemical rotamerization processes must take into consideration the fact that only the SC form is reactive. Very interestingly, the $\nu(\mathrm{C}=\mathrm{O})$ coordinate in this conformer belongs to the $\mathrm{A}^{\prime}$ symmetry, while the torsional modes $\tau(\mathrm{C}=\mathrm{O})$ and $\tau(\mathrm{C}=\mathrm{O})$ that define the possible reaction coordinates belong to the $\mathrm{A}^{\prime \prime}$ symmetry species. Thus, no direct energy transfer from the $\nu(\mathrm{C}=\mathrm{O})$ to the torsions may occur, the mechanism involved requiring participation of non-fundamental vibrations which can mix the relevant coordinates.

As suggested previously [8], the $\nu(\mathrm{C}=\mathrm{O})$ mode of the SC conformer of chlorocetic acid interacts with the first overtone of $\gamma\left(\mathrm{CH}_{2}\right)\left(\mathrm{A}^{\prime}\right)$ through a Fermi resonance mechanism. Thus, by irradiating the sample at $1805 \mathrm{~cm}^{-1}$, energy is transferred not only to the $\mathrm{C}=\mathrm{O}$ stretching, but also to the $\gamma\left(\mathrm{CH}_{2}\right)$ mode through its first overtone. Then, as the $\gamma\left(\mathrm{CH}_{2}\right)$ fundamental belongs to the same symmetry species $\left(\mathrm{A}^{\prime \prime}\right)$ as the $\tau(\mathrm{C}-\mathrm{C})$ and $\tau(\mathrm{C}-\mathrm{O})$ torsions, irradiation in the $\nu(\mathrm{C}=\mathrm{O})$ region may be effective in promoting rotamerization, in the SC conformer, $\gamma\left(\mathrm{CH}_{2}\right)$ is considerably mixed with $\gamma(\mathrm{C}=\mathrm{O})$, and these two modes with $\tau(\mathrm{C}-\mathrm{O})$ and $\tau(\mathrm{C}-\mathrm{C})$ (see Table 1$)$ and the rotamerization reactions may occur. In contrast, in the SKC form, $\gamma\left(\mathrm{CH}_{2}\right)$ does not mix appreciably with any relevant coordinate and the reactions cannot take place. Finally, in the case of the AT conformer, while $\gamma\left(\mathrm{CH}_{2}\right)$ and $\gamma(\mathrm{C}=\mathrm{O})$ mix with each other, these two coordinates do not mix with torsions, which very interestingly, are essentially pure vibrations in this conformation. Hence, also for this form, rotamerization reactions cannot be induced by laser irradiation in the $\nu(\mathrm{C}=\mathrm{O})$ region.

The results obtained also indicate that a concerted rotation about the $\mathrm{C}-\mathrm{C}$ and $\mathrm{C}-\mathrm{O}$ bonds shall be involved in the $\mathrm{SC} \rightarrow \mathrm{AT}$ rotamerization, instead of a multi-step process involving separate $\mathrm{C}-\mathrm{C}$ and $\mathrm{C}-\mathrm{O}$ rotamerizations corresponding to $\mathrm{S} \rightarrow(\mathrm{SK}) \rightarrow \mathrm{A}$ and $\mathrm{C} \rightarrow \mathrm{T}$ individual processes, one at a time. In fact, as was shown above, the AT form cannot be obtained from the SKC form upon laser irradiation in the $\nu(\mathrm{C}=\mathrm{O})$ region, following the $\mathrm{SC} \rightarrow \mathrm{SKC} \rightarrow \mathrm{AT}$ mechanism. In turn, the alternative way of obtaining the AT form from the SC conformer is via the ST form $(\mathrm{SC} \rightarrow \mathrm{ST} \rightarrow \mathrm{SKT} \rightarrow \mathrm{AT})$, but the first step of this reaction does not occur as the $\mathrm{CO}$ laser photon energy (ca. $22 \mathrm{~kJ} \mathrm{~mol}^{-1}$ ) is not high enough to promote $\mathrm{SC} \rightarrow$ ST transformation. 


\section{2. $U V$-induced reactivity and intermolecular} interactions in $\mathrm{CH}_{3} \mathrm{CH}=\mathrm{CHCOOH}$

Crotonic acid may exist as two different isomers, $E$ and $Z$-crotonic acid, differing in the relative position of the methyl and carboxyl groups around the double bond. For the isolated molecule situation (monomeric species) $E$-crotonic acid has four different stable conformations, while the $Z$ isomer may exist in three different forms (see Fig. 3). As expected, the $s$-cis $(\mathrm{C}-\mathrm{O})$ conformers $(E-c c$ and $E$-ct or Z-cc and $Z$ - $c t$ ) have a considerably lower energy than the $s$ trans $(\mathrm{C}-\mathrm{O})$ or non-planar forms $(E-t c$ and $E$ - $n p$ or $Z$ - $t c$ ). For both $E$ and $Z$ isomers, the conformational ground state corresponds to the $c c$ form, where both $\mathrm{O}=\mathrm{C}-\mathrm{O}-\mathrm{H}$ and $\mathrm{C}=\mathrm{C}-\mathrm{C}=\mathrm{O}$ diheadral angles are equal to $0^{\circ}$. The second $s$-cis $(\mathrm{C}-\mathrm{O})$ form $(c t$, which has the $\mathrm{C}=\mathrm{C}-\mathrm{C}=\mathrm{O}$ axis assuming the $s$-trans configuration) has a slightly higher energy than this form, while the remaining conformers have energies which are above that of the corresponding most stable form by more than $30 \mathrm{~kJ} \mathrm{~mol}^{-1}$. The $6-31 \mathrm{G}^{*}$ calculated energy of the most stable form of $Z$-crotonic acid is ca. $10 \mathrm{~kJ} \mathrm{~mol}^{-1}$ higher than that of the most stable form of $E$-crotonic acid. This increase in energy in going from $E$ - $c c$ to $Z$ - $c c$ can be ascribed to a reduced methyl/carbonyl distance in the latter molecule, which leads to steric strain.

The IR spectrum of $E$-crotonic acid trapped in an Ar matrix (Fig. 4) shows two sets of bands with different behavior upon irradiation of the sample with UV light $(\lambda<262 \mathrm{~nm}$; in the long-wave wing of the ethylenic $\pi-\pi^{*}$ absorption band), indicating that, initially, two conformers of this molecule are present in the matrix. These were identified as corresponding to the more stable $E$-cc and $E$-ct conformers; irradiation promotes $E$ - $c c \rightarrow E$ - $c t$ isomerization (Fig. 5). In addition, new bands appear in the spectrum, testifying the appearance of new species. When the irradiation is undertaken at wavelengths smaller than $243 \mathrm{~nm}$, bands of $\mathrm{CO}, \mathrm{CO}_{2}$ and $\mathrm{H}_{2} \mathrm{O}$ appear in the spectrum, indicating the beginning of the acid photodissociation processes.

When irradiation in the $262-243 \mathrm{~nm}$ is carried out, two groups of bands belonging to new species, exhibiting different intensity dependences on the irradiation wavelength were found. The comparison of the deconvoluted IR spectra of the individual

\section{E-crotonic acid}
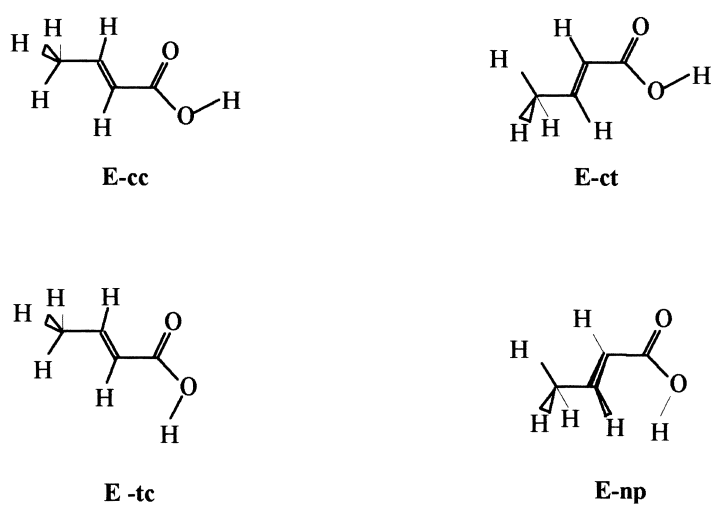

Z-crotonic acid
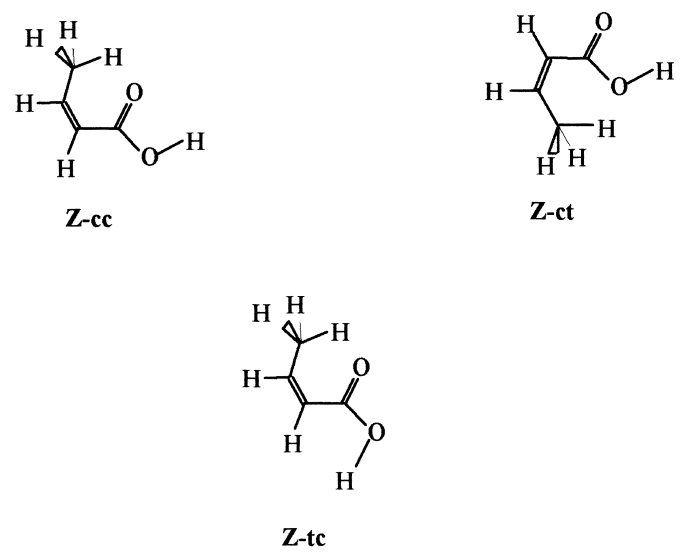

Fig. 3. Conformers of $E$ - and Z-crotonic acid (monomer).

experimentally observed molecules with the $6-31 \mathrm{G}^{*}$ calculated spectra clearly shows that these new molecules correspond to the two s-cis $(\mathrm{C}-\mathrm{O})$ conformers of $Z$-crotonic acid (Z-cc and Z-ct; Fig. 6). It is worth noting that the $E$-crotonic acid $\rightarrow Z$ crotonic acid isomerization is both faster and more pronounced than the $\mathrm{C} \alpha-\mathrm{C}$ rotamerization process discussed earlier that promotes $E$-cc $\rightarrow E$-ct conversion. Although either volume restrictions imposed by the matric or relative masses of rotating groups may also explain this observation, it is more probable that the double bond character of the $\mathrm{C}=\mathrm{C}$ bond strongly reduces upon electronic excitation and, consequently, its associated energy barrier to internal rotation becomes lower in the excited state than that associated 
(c)

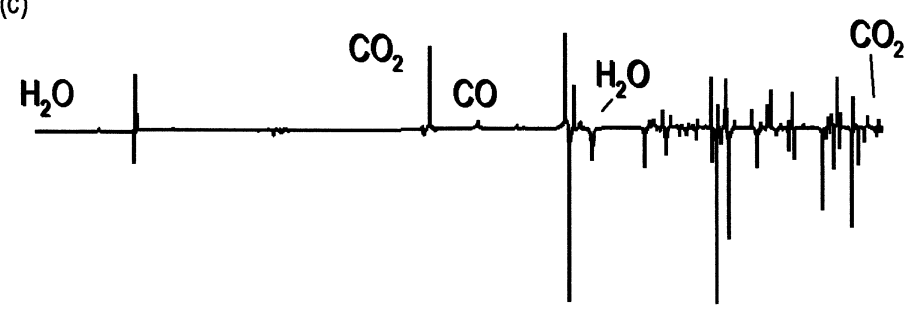

(b)

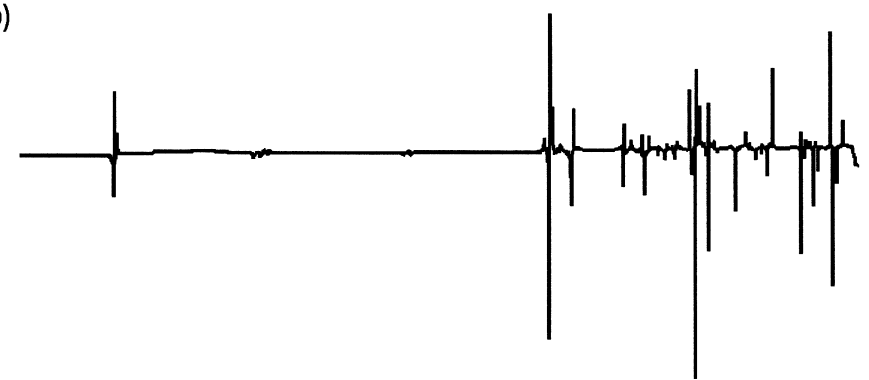

(a)

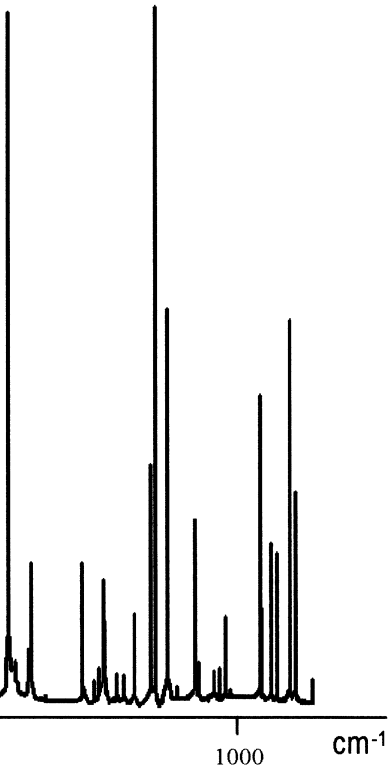

Fig. 4. (a) IR spectrum of $E$-crotonic acid isolated in an Ar matrix after deposition at $18 \mathrm{~K}$, and the difference spectra obtained by subtracting this spectrum from (b) the spectrum obtained after UV irradiation in the 143-262 nm region and (c) from the spectrum obtained after irradiation below $243 \mathrm{~nm}$.

with the rotation around the $\mathrm{C} \alpha-\mathrm{C}$ bond. It is also interesting to note that photo induced isomerization reactions about the $\mathrm{C}=\mathrm{C}$ bond in $\beta$-substituted $\alpha, \beta$-unsaturated carboxylic molecules of general formula $\mathrm{R}-\mathrm{CH}=\mathrm{CH}-\mathrm{C}(=\mathrm{O}) \mathrm{OR}^{\prime}\left(\mathrm{R}, \mathrm{R}^{\prime}=\mathrm{H}\right.$ or alkyl $)$, leading to cis $\rightarrow$ trans isomerization about this bond, have also been recently proposed to occur during the recording of resonance Raman spectra of $\alpha, \beta$-unsaturated carboxylic esters bound to serine proteases [19]. Besides its relevance to the biochemical studies on serine proteases, this type of photochemical reactions also appears to be useful in organic synthesis, thus stressing the interest of looking at them in greater detail. 
(E-c)

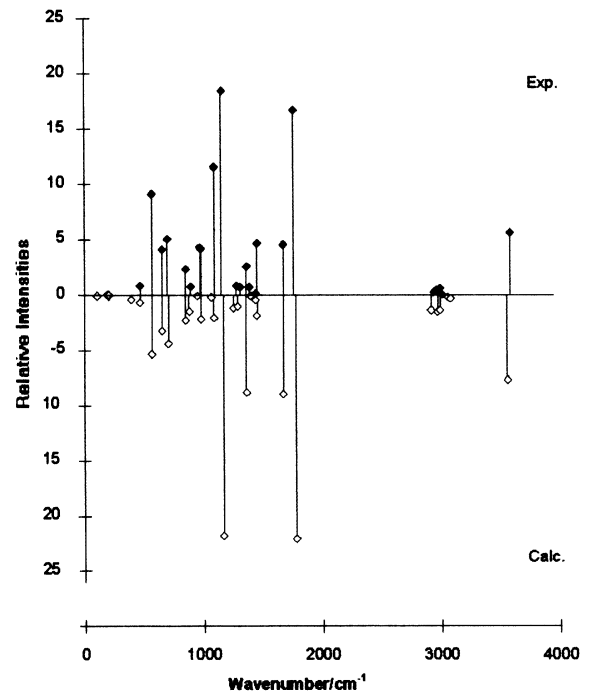

(E-ct)

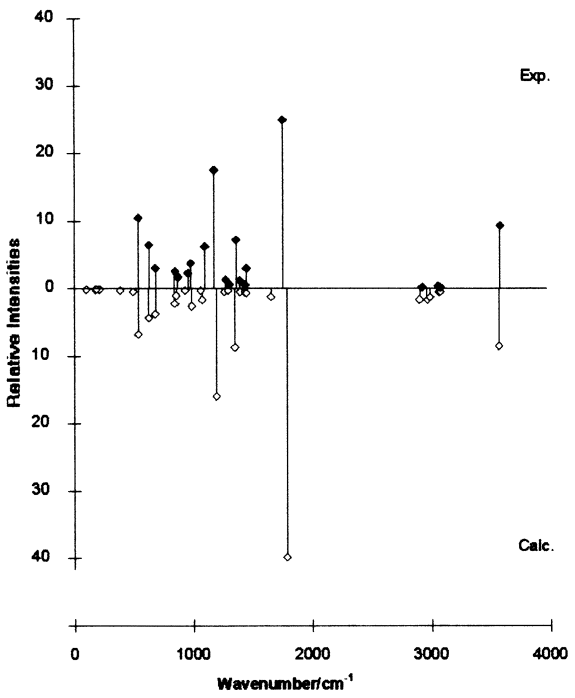

Fig. 5. Deconvoluted experimental IR and 6-31G* calculated spectra of the $E$ - $c c$ and $E$-ct conformers of $E$-crotonic acid. Experimental relative intensities correspond to intensities normalized to the total intensity of all observed bands ascribed to a given conformer $\left(I=100 I^{\mathrm{obs}} / \Sigma_{i=1, n} I_{i}^{\mathrm{obs}}\right)$; calculated relative intensities are normalized to the total calculated intensity of all bands which have an experimentally observed counterpart.

$(\mathbf{z - c c )}$

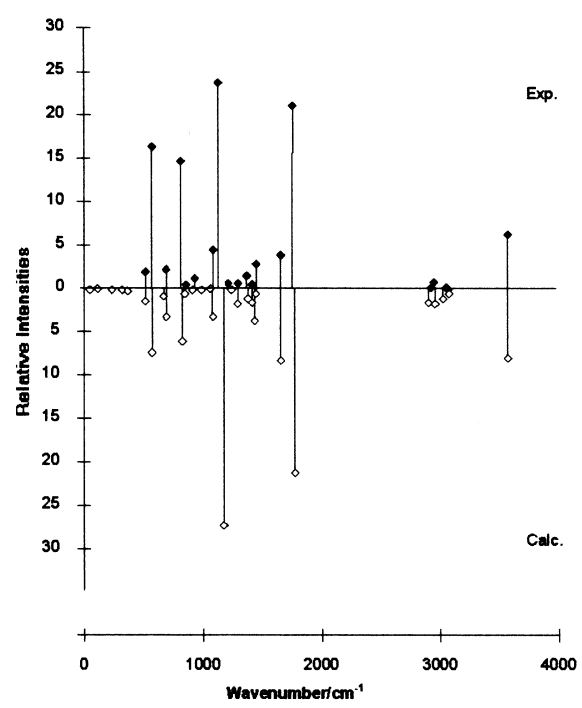

$(z-c t)$

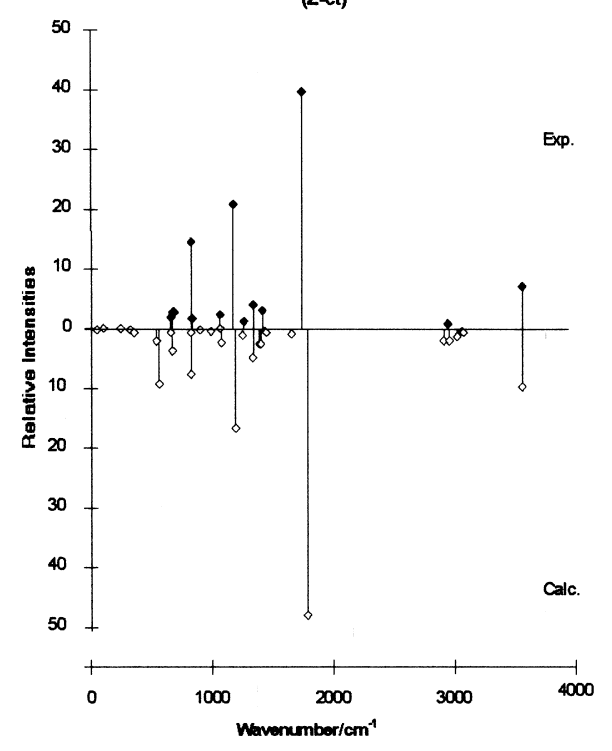

Fig. 6. Deconvoluted experimental IR and 6-31G* calculated spectra of the $Z$ - $c c$ and Z-ct conformers of Z-crotonic acid. Experimental relative intensities correspond to intensities normalized to the total intensity of all observed bands ascribed to a given conformer $\left(I=100 I^{\mathrm{obs}} / \Sigma_{i=1, n} I_{i}^{\mathrm{obs}}\right)$; calculated relative intensities are normalized to the total calculated intensity of all bands which have an experimentally observed counterpart. 
As referred to before, upon irradiation at wavelenghts smaller than $243 \mathrm{~nm}$, crotonic acid begins to decompose. This can be easily detected spectroscopically, as characteristic bands of $\mathrm{CO}, \mathrm{CO}_{2}$ and $\mathrm{H}_{2} \mathrm{O}$ appear in the spectra after irradiation. Very interestingly, the amount of $\mathrm{CO}_{2}$ produced by photodecomposition is considerably higher than that of both $\mathrm{CO}$ and $\mathrm{H}_{2} \mathrm{O}$. Besides the bands arising from $\mathrm{CO}, \mathrm{CO}_{2}$ and $\mathrm{H}_{2} \mathrm{O}$ other bands obtained from photodegradation products could also been observed and assigned to formic acid, propene and propyne. As the reactant molecule is a well-isolated crotonic acid molecule, the photochemical transformations pertain to reactions confined to the matrix cage. This fact and stoichiometric considerations imply that $\mathrm{CO}$ is trapped together with $\mathrm{H}_{2} \mathrm{O}$ and propyne, while $\mathrm{CO}_{2}$ with propene. Most of the observed frequencies are slightly different from the literature values [20-24], clearly indicating that the products of photodecomposition which are trapped in the same matrix cage interact with each other. In particular, the frequencies of $\mathrm{CO}$ were measured at $2147.4,2138.2$ and $2130.1 \mathrm{~cm}^{-1}$, the highest frequency band corresponding to a frequency typical of a hydrogen-bonded complex of $\mathrm{CO}$ [23-25].

Thus, the results indicate that under irradiation below $243 \mathrm{~nm}$, crotonic acid decomposes following two different main pathways:

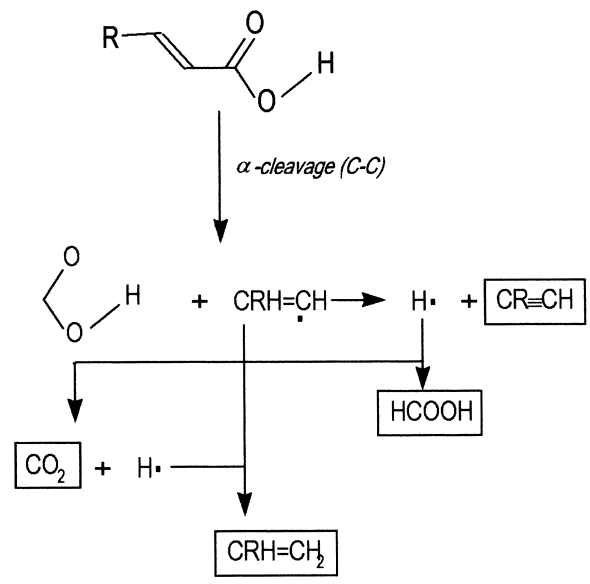

It is well known that the mesomerism within the $\mathrm{C}=\mathrm{C}-\mathrm{C}=\mathrm{O}$ fragment in $\alpha, \beta$-unsaturated carboxylic compounds, which leads to a stronger $\mathrm{C} \alpha-\mathrm{C}$ bond, is less important for an s-cis $(\mathrm{C} \alpha-\mathrm{C})$ conformation than for the $s$-trans $(\mathrm{C} \alpha-\mathrm{C})$ form $[26,27]$. In contrast, the $\mathrm{C}-\mathrm{O}$ band is weaker in the $s$-s-trans $(\mathrm{C} \alpha-\mathrm{C})$ form than in the s-cis $(\mathrm{C} \alpha-\mathrm{C})$ conformer, as the mesomerism within the carboxylic group (that increases the strengths the $\mathrm{C}-\mathrm{O}$ bond) competes with the mesomerism within the $\mathrm{C}=\mathrm{C}-\mathrm{C}=\mathrm{O}$ fragment to increase the electronic charge of the carbonyl oxygen atom. These effects determine the preferred pathway for photodecomposition starting from the two most stable conformers of $E$-crotonic acid: form $E$ - $c c$ suffers predominantly photochemical cleavage of the $\mathrm{C} \alpha-\mathrm{C}$ bond (pathway I), while form $E-c t$ photodecomposes mainly through cleavage of the $\mathrm{C}-\mathrm{O}$ bond (pathway II). As the $s-c i s(\mathrm{C} \alpha-\mathrm{C})$ form is in the conformational ground state, the observed prevalence of the reactions corresponding to pathway (I) over those related with (II) can be easily understood. Further, for $s$-cis $(\mathrm{C}-\mathrm{O})$ carboxylates, the cleavage of the acyl bond is generally preferred to the $\mathrm{C}-\mathrm{O}$ cleavage [28], this property also contributing to the observed prevalence of pathway (I) when compared to (II).

In the crystalline phase, $E$-crotonic acid forms cyclic hydrogen-bonded dimers. Its structure has been determined by X-ray diffraction [29] and it was shown that both molecules forming the dimeric

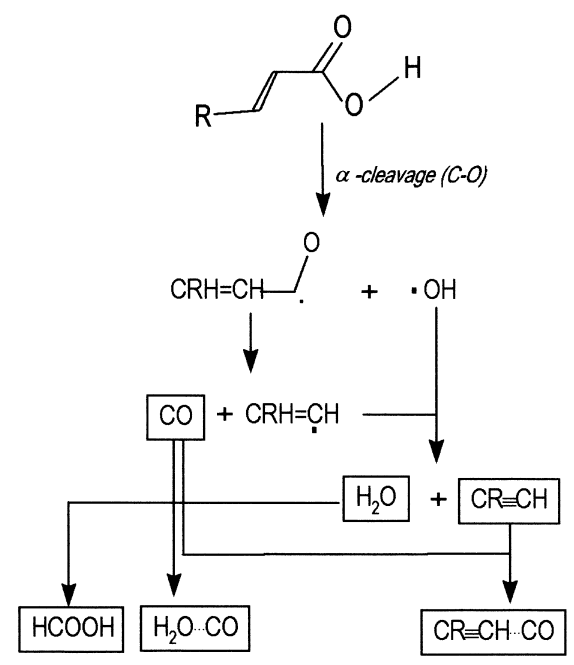


unit adopt the s-cis conformation about the $\mathrm{C} \alpha-\mathrm{C}$ bond. In addition, the dimers were found to pack in the crystal as shown schematically in Fig. 5, exhibiting a $\mathrm{C} \alpha-\mathrm{C} \ldots \mathrm{O}=$ inter-dimer contact with a $\mathrm{C}=\mathrm{O} \ldots \mathrm{H}^{\prime}$ angle of $\approx 130^{\circ}[30,31]$.

Calculations made at the ab initio 6-31G* and semiempirical AM1 levels of theory were able to reproduce monomer properties adequately, in particular the energy differences between the two most stable forms $\left(\Delta E_{(E-c t)-(E-c c)}=2.8 \mathrm{~kJ} \mathrm{~mol}^{-1}\right.$, ab initio; $1.7 \mathrm{~kJ} \mathrm{~mol}^{-1}$, AM1), the relative order of magnitude of their electric dipole moments $\left(\mu_{E-c t} / \mu_{E-c c}\right)=1.48$, ab initio; 1.28 AM1), and most of changes in the geometrical parameters associated with the $E$ - $c c \rightarrow E$-ct isomerization, as well as the changes in geometries associated with the dimer formation. However, both energetic and geometric results clearly indicate that the 6$31 \mathrm{G}^{*}$ ab initio calculations predict a considerably stringer hydrogen bond within the dimer than AM1 calculations. Indeed, the calculated percent changes in the $\mathrm{C}=\mathrm{O}, \mathrm{C}-\mathrm{O}$ and $\mathrm{O}-\mathrm{H}$ bond lengths upon dimer formation are $1.17 \%, \quad-1.17 \%$ and $1.48 \%$ (6$31 \mathrm{G}^{*}$ ) and $0.31 \%, \quad-0.59 \%$ and $0.54 \%$ (AM1), respectively, while $=\mathrm{O} \ldots \mathrm{H}$ hydrogen bond distance is predicted to be considerably shorter by the 6$31 \mathrm{G}^{*}$ calculations than by AM1 method (181.97) vs. $209.19 \mathrm{pm}$ ) and the calculated energy of dimer formation (measured as $E_{\text {dimer }}-2 \times E_{\text {monomer }}$ ) is significantly larger at the ab initio than at the semiempirical level $\left(-65.990\right.$ vs. $\left.-25.93 \mathrm{~kJ} \mathrm{~mol}^{-1}\right)$. The $=$ O...H.O hydrogen bond is predicted by both methods to be nearly linear and the $\mathrm{C}=\mathrm{O} \ldots \mathrm{H}$ angle to be $\approx 130$ $135^{\circ}$. Interestingly, this latter angle is similar to the reported $\mathrm{C}=\mathrm{O} \ldots \mathrm{H}^{\prime}$ angle associated with the interdimer $\mathrm{C}=\mathrm{O} \ldots \mathrm{H}^{\prime}-\mathrm{C} \alpha$ contact in crystalline $E$-crotonic acid [30,31] (see also Fig. 7).

The dimer of $E$-crotonic acid has a $\mathrm{C}_{2 \mathrm{~h}}$ symmetry and IR and Raman bands should be, in principle, noncoincident. However, in general vibrational selection rules do not hold rigorously in hydrogen-bonded systems because the coupling between monomer units is relatively weak [29,32] and, consequently, is not able to cause observable frequency differences between the in-phase and out-of-phase vibrations. In-phase vibrations may however still be expected to be stronger in the Raman spectrum than in the IR spectrum, and out-of-phase vibrations to be stronger in the IR spectrum.

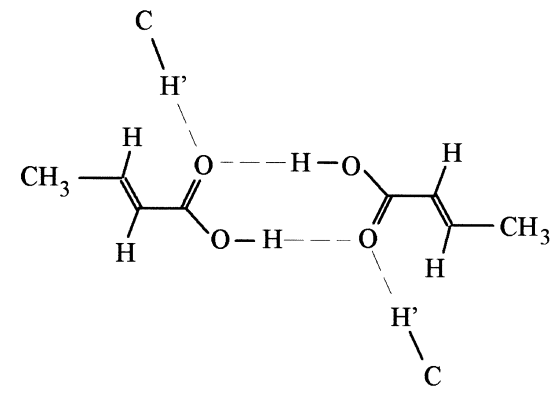

Fig. 7. Schematic representation of the packing motif found in cyrstalline $E$-crotonic acid, showing $\mathrm{C} \alpha-\mathrm{H}^{\prime} \ldots \mathrm{O}=$ inter-dimer contacts.

Considering the monomer frequencies obtained for the molecule isolated in an Ar matrix and the theoretical predictions, it was possible to make a detailed assignment of both the IR and Raman spectra of the crystal (Table 2). As expected, some bands forbidden by symmetry were observed (e.g., the $\nu \mathrm{C}=\mathrm{O} \mathrm{A} \mathrm{A}_{\mathrm{g}}$ inphase vibration gives rise to the IR band at $1694 \mathrm{~cm}^{-1}$ and the $\delta \mathrm{C}-\mathrm{C}=\mathrm{O} \mathrm{B}_{\mathrm{u}}$ mode gives rise to the low intensity Raman band at $689 \mathrm{~cm}^{-1}$ ). When compared with the frequency observed for the monomer $\left(1271 \mathrm{~cm}^{-1}\right), \delta \mathrm{C} \alpha-\mathrm{H}$ appears considerably red shift in the spectra of crystalline $E$-crotonic acid. Very interestingly, the calculations predict that a blue shift should occur in this mode upon dimer formation. The observed red shift must then be ascribed to interdimer contacts and thus the spectroscopic results are in consonance with X-ray data [29-31], revealing the existence in the crystalline phase of an inter-dimer $\mathrm{C} \alpha-\mathrm{H} \ldots \mathrm{O}=$ hydrogen bond. Unfortunately, the frequency of the $\nu \mathrm{C} \alpha-\mathrm{H}$ stretching mode in the monomer is not precisely known, as the band arising from this mode could not be observed in the matrix isolated monomer, and no comparison can then be made between the frequencies of this vibration in the monomer and in crystalline $E$-crotonic acid, in order to obtain further spectroscopic support to the existence of this inter-dimer $\mathrm{C} \alpha-\mathrm{H} . . \mathrm{O}=$ contact in the crystal. The torsional vibrations (sometimes better described in the crystalline phase as hybrid coordinates involving other out-of-plane vibrations, such as $\gamma \mathrm{C}=\mathrm{O})-$ in particular $\tau \mathrm{C}-\mathrm{O}$ - and the $\delta \mathrm{COH}$ hydroxyl in-plane bending mode are strongly blue shifted in the crystal when compared with the 
Table 2

Vibrational wavenumbers and intensities for $E$-crotonic acid dimer $\left(200-4000 \mathrm{~cm}^{-1}\right.$ region) ${ }^{\mathrm{a}}$

\begin{tabular}{|c|c|c|c|c|c|c|c|c|c|c|c|}
\hline \multirow[t]{2}{*}{ Approximate description } & \multirow[t]{2}{*}{ Symmetry } & \multicolumn{3}{|l|}{ Exp. } & \multicolumn{3}{|c|}{ Calc. (AM1) } & \multicolumn{4}{|c|}{ Calc. $\left(6-31 G^{*}\right)$} \\
\hline & & $\nu$ & $I_{\mathrm{IR}}^{\mathrm{b}}$ & $I_{\mathrm{R}}^{\mathrm{b}}$ & $\nu^{\text {scaled }}$ & $I_{\mathrm{IR}}{ }^{\mathrm{c}}$ & $\Delta \nu^{\mathrm{d}}$ & $\nu^{\text {scaled }}$ & $I_{\mathrm{IR}}^{\mathrm{c}}$ & $I_{\mathrm{R}}^{\mathrm{c}}$ & $\Delta \nu^{\mathrm{d}}$ \\
\hline \multirow[t]{2}{*}{$\nu \mathrm{O}-\mathrm{H}$} & $\mathrm{Bu}$ & $\approx 3000$ & 46.5 & & 3530 & 29.5 & 530 & 3334 & 42.7 & & 334 \\
\hline & $\mathrm{Ag}$ & n.o. & & & 3519 & & & 3294 & & 30.6 & \\
\hline \multirow[t]{2}{*}{$\nu \mathrm{C}_{\alpha}-\mathrm{H}$} & $\mathrm{Bu}$ & 3063 & 0.6 & & 3075 & 3.7 & 12 & 3071 & 0.2 & & 8 \\
\hline & $\mathrm{Ag}$ & 3058 & & 2.6 & 3075 & & 17 & 3071 & & 7.1 & 13 \\
\hline \multirow{2}{*}{$\nu \mathrm{C}_{\beta}-\mathrm{H}$} & $\mathrm{Bu}$ & 3040 & 0.4 & & 3016 & 1.1 & -24 & 3055 & 0.1 & & 15 \\
\hline & $\mathrm{Ag}$ & 3039 & & 8.4 & 3016 & & -23 & 3055 & & 7.1 & 16 \\
\hline \multirow[t]{2}{*}{$\nu \mathrm{CH}_{3}$ as. } & $\mathrm{Bu}$ & 2984 & 0.9 & & 2990 & 0.2 & 6 & 2982 & 0.7 & & -2 \\
\hline & $\mathrm{Ag}$ & 2978 & & 6.1 & 2990 & & 12 & 2982 & & 10.4 & 4 \\
\hline \multirow[t]{2}{*}{$\nu \mathrm{CH}_{3}$ as. } & $\mathrm{Au}$ & 2957 & 0.6 & & 2958 & 0.4 & 1 & 2966 & 0.8 & & 9 \\
\hline & $\mathrm{Bg}$ & 2957 & & 6.2 & 2958 & & 1 & 2966 & & 10.3 & 9 \\
\hline \multirow{2}{*}{$\nu \mathrm{CH}_{3} \mathrm{~s}}$. & $\mathrm{Bu}$ & 2926 & 1.1 & & 2929 & 0.3 & 3 & 2904 & 0.9 & & -22 \\
\hline & $\mathrm{Ag}$ & 2925 & & 21.7 & 2929 & & 4 & 2904 & & 27.3 & -21 \\
\hline \multirow[t]{2}{*}{$\nu \mathrm{C}=\mathrm{O}$} & $\mathrm{Bu}$ & 1703 & 10.9 & & 1745 & 18.6 & 42 & 1734 & 13.7 & & 31 \\
\hline & $\mathrm{Ag}$ & 1694 & & 1.9 & 1733 & & 39 & 1700 & & 1.1 & 6 \\
\hline \multirow[t]{2}{*}{$\nu \mathrm{C}=\mathrm{C}$} & $\mathrm{Bu}$ & $1654^{\mathrm{e}}$ & 8.0 & & 1667 & 6.7 & 13 & 1660 & 8.1 & & 6 \\
\hline & $\mathrm{Ag}$ & 1657 & & 17.2 & 1668 & & 11 & 1664 & & 16.2 & 7 \\
\hline \multirow[t]{2}{*}{$\nu \mathrm{C}-\mathrm{O}+\delta \mathrm{C}-\mathrm{O}-\mathrm{H}$} & $\mathrm{Bu}$ & 1449 & 2.7 & & 1351 & 5.1 & -98 & 1400 & 5.9 & & -49 \\
\hline & $\mathrm{Ag}$ & n.o. & & 1349 & & & 1418 & & 1.8 & & \\
\hline \multirow[t]{2}{*}{$\delta \mathrm{CH}_{3}$ as. } & $\mathrm{Ag}$ & 1443 & & 3.4 & 1449 & & 6 & 1445 & & 3.8 & 2 \\
\hline & $\mathrm{Bu}$ & 1442 & 0.9 & & 1449 & 0.6 & 7 & 1444 & 1.7 & & 2 \\
\hline \multirow{2}{*}{$\delta \mathrm{CH}_{3}$ as. } & $\mathrm{Bg}$ & 1429 & & 2.8 & 1436 & & 7 & 1434 & & 2.5 & 5 \\
\hline & $\mathrm{Au}$ & 1421 & 1.3 & & 1436 & 0.3 & 14 & 1434 & 0.2 & & 13 \\
\hline \multirow[t]{2}{*}{$\delta \mathrm{CH}_{3} \mathrm{~s}$. } & $\mathrm{Ag}$ & 1384 & & 3.2 & 1374 & & -10 & 1387 & & 1.7 & 3 \\
\hline & $\mathrm{Bu}$ & 1380 & 0.9 & & 1374 & 0.2 & -6 & 1387 & 0.1 & & 7 \\
\hline$\delta \mathrm{CO}-\mathrm{H}+\nu \mathrm{C}-\mathrm{O}$ & $\mathrm{Bu}$ & 1315 & 5.3 & & 1169 & 16.6 & -146 & 1221 & 6.7 & & -94 \\
\hline & $\mathrm{Ag}$ & $1311^{\mathrm{f}}$ & & 1.0 & 1165 & & -146 & 1217 & & 0.6 & -94 \\
\hline$\delta \mathrm{C}_{\beta}-\mathrm{H}$ & $\mathrm{Bu}$ & 1295 & 2.8 & & 1307 & 0.1 & 12 & 1282 & 0.9 & & -13 \\
\hline & $\mathrm{Ag}$ & 1291 & & 3.7 & 1307 & & 16 & 1282 & & 3.8 & -9 \\
\hline$\delta \mathrm{C}_{\alpha}-\mathrm{H}$ & $\mathrm{Bu}$ & 1224 & 4.4 & & 1275 & 0.3 & 51 & 1292 & 5.6 & & 68 \\
\hline & $\mathrm{Ag}$ & 1220 & & 1.4 & 1275 & & 55 & 1301 & & 1.5 & 81 \\
\hline$\gamma \mathrm{CH}_{3}$ & $\mathrm{Ag}$ & 1107 & & 0.7 & 1092 & & -15 & 1087 & & 0.7 & -20 \\
\hline & $\mathrm{Bu}$ & 1104 & 0.9 & & 1092 & 0.7 & -12 & 1088 & 0.2 & & -16 \\
\hline$\gamma \mathrm{CH}_{3}+\gamma \mathrm{C}_{\beta}-\mathrm{H}$ & $\mathrm{Au}$ & 1052 & 0.3 & & 1064 & $<0.1$ & 12 & 1064 & 0.1 & & 12 \\
\hline & $\mathrm{Bg}$ & 1047 & & 1.0 & 1064 & & 17 & 1064 & & 0.4 & 17 \\
\hline$\nu \mathrm{C}-\mathrm{C}$ & $\mathrm{Ag}$ & 996 & & 1.0 & 972 & & -24 & 958 & & 0.4 & -38 \\
\hline & $\mathrm{Bu}$ & 987 & 0.3 & & 972 & $<0.1$ & -15 & 958 & $<0.1$ & & -29 \\
\hline$\gamma \mathrm{C}_{\alpha}-\mathrm{H}$ & $\mathrm{Bg}$ & 967 & & 0.3 & 976 & & 9 & 980 & & $<0.1$ & 13 \\
\hline & $\mathrm{Au}$ & 963 & 3.5 & & 976 & 4.9 & 13 & 980 & 1.2 & & 17 \\
\hline$\nu \mathrm{C}_{\alpha}-\mathrm{C}$ & $\mathrm{Bu}$ & 921 & 1.2 & & 890 & 0.2 & -31 & 885 & 0.8 & & -36 \\
\hline & $\mathrm{Ag}$ & 918 & & 0.6 & 891 & & -27 & 885 & & 0.3 & -33 \\
\hline$\tau \mathrm{C}-\mathrm{O}+\gamma \mathrm{C}=\mathrm{O}$ & $\mathrm{Au}$ & 905 & 1.1 & & 704 & 4.4 & -201 & 869 & 5.8 & & -36 \\
\hline & $\mathrm{Bg}$ & 902 & & 0.7 & 693 & & -209 & 851 & & 1.7 & -51 \\
\hline$\gamma \mathrm{C}_{\beta}-\mathrm{H}+\gamma \mathrm{CH}_{3}$ & $\mathrm{Au}$ & 844 & 0.9 & & 841 & $<0.1$ & -3 & 838 & 0.6 & & -6 \\
\hline & $\mathrm{Bg}$ & 843 & & 2.2 & 841 & & -2 & 805 & & 0.5 & -38 \\
\hline$\delta \mathrm{O}=\mathrm{C}-\mathrm{O}$ & $\mathrm{Bu}$ & 703 & 2.0 & & 646 & 2.4 & -57 & 680 & 1.7 & & -23 \\
\hline & $\mathrm{Ag}$ & 685 & & 4.3 & 649 & & -36 & 671 & & 0.4 & -14 \\
\hline$\gamma \mathrm{C}=\mathrm{O}+\tau \mathrm{C}-\mathrm{O}$ & $\mathrm{Bg}$ & 674 & & 0.5 & 600 & & -74 & 677 & & 0.3 & 3 \\
\hline & $\mathrm{Au}$ & n.o. & & & 617 & 2.5 & & 673 & $<0.1$ & & \\
\hline$\delta \mathrm{C}-\mathrm{C}=\mathrm{O}$ & $\mathrm{Bu}$ & 519 & 0.9 & & 483 & 0.3 & -36 & 496 & 0.5 & & -23 \\
\hline & $\mathrm{Ag}$ & 488 & & 3.2 & 475 & & -13 & 481 & & 0.3 & -7 \\
\hline$\delta \mathrm{C}-\mathrm{C}_{\beta}=\mathrm{C}$ & $\mathrm{Ag}$ & 417 & & 2.9 & 403 & & -14 & 408 & & 0.5 & -9 \\
\hline
\end{tabular}


Table 2 (continued)

\begin{tabular}{|c|c|c|c|c|c|c|c|c|c|c|c|}
\hline \multirow[t]{2}{*}{ Approximate description } & \multirow[t]{2}{*}{ Symmetry } & \multicolumn{3}{|l|}{ Exp. } & \multicolumn{3}{|c|}{ Calc. (AM1) } & \multicolumn{4}{|c|}{ Calc. $\left(6-31 G^{*}\right)$} \\
\hline & & $\nu$ & $I_{\mathrm{IR}}^{\mathrm{b}}$ & $I_{\mathrm{R}}^{\mathrm{b}}$ & $\nu^{\text {scaled }}$ & $I_{\mathrm{IR}}{ }^{\mathrm{c}}$ & $\Delta \nu^{\mathrm{d}}$ & $\nu^{\text {scaled }}$ & $I_{\mathrm{IR}}{ }^{\mathrm{c}}$ & $I_{\mathrm{R}}^{\mathrm{c}}$ & $\Delta \nu^{\mathrm{d}}$ \\
\hline & $\mathrm{Bu}$ & 402 & 0.4 & & 394 & 0.6 & -8 & 396 & 0.3 & & -6 \\
\hline \multirow[t]{2}{*}{$\delta \mathrm{C}=\mathrm{C}_{\alpha}-\mathrm{C}$} & $\mathrm{Bu}$ & 256 & 1.2 & & 246 & 0.4 & -10 & 252 & 0.5 & & -4 \\
\hline & $\mathrm{Ag}$ & 238 & & 0.4 & 210 & & -28 & 234 & & $<0.1$ & -4 \\
\hline \multirow[t]{2}{*}{$\tau \mathrm{C}=\mathrm{C}$} & $\mathrm{Bg}$ & 231 & & 0.5 & 202 & & -29 & 206 & & $<0.1$ & -25 \\
\hline & $\mathrm{Au}$ & n.o. & & & 200 & $<0.1$ & & 199 & $<0.1$ & & \\
\hline
\end{tabular}

${ }^{\mathrm{a}} \nu$, stretching; $\delta$, bending; $\omega$, wagging; t, twisting; $\gamma$, rocking; $\tau$, torsion; n.o., not observed; s, symmetric; as., asymmetric.

${ }^{\mathrm{b}}$ Experimental IR and Raman intensities are normalised values to the total intensity of all observed bands.

${ }^{\mathrm{c}}$ Calculated intensities are normalised values to the total calculated intensity of all bands which have an experimentally observed counterpart.

${ }^{\mathrm{d}} \Delta \nu=\nu^{\mathrm{obs}}-\nu^{\text {scaled }}$.

${ }^{\mathrm{e}}$ A second band, caused by the Fermi resonance, is observed at $1637 \mathrm{~cm}^{-1}$.

${ }^{\mathrm{f}}$ A second band, arising from Fermi resonance, is observed at $1287 \mathrm{~cm}^{-1}$.

corresponding modes in the monomeric species. This effect is correctly predicted (though underestimated) by the calculations, and results both from intra-dimer hydrogen bonding and from inter-dimer crystal packing forces. These two kinds of interactions considerably restrict the movements of the atoms in the crystal (specially those of the hydroxyl hydrogen atoms), thus leading to an increase in the force constants and, consequently, to a frequency shift to higher values. Similar blue shifts upon going from the matrix-isolated molecule to the crystalline state were also observed previously for the same vibrations in acrylic acid [26].

\subsection{Structural characterization of the $\alpha$ and $\beta$ crystalline varieties of $\mathrm{CH}_{2}(\mathrm{COOH})_{2}$}

Malonic acid may exist in three crystalline varieties, depending on the temperature of the sample. Phase $\gamma$ exists at temperatures below $48 \mathrm{~K}$ [33], phase $\beta$ is stable in the temperature range $48-360 \mathrm{~K}$ [34-36] and phase $\alpha$ above $360 \mathrm{~K}[34,37]$. In phase $\beta$, crystals are triclinic, having two monomeric units per unit cell; each unit cell shows two crytallographically nonequivalent carboxylate rings which stay nearly orthogonal to each other [36]. Phase $\alpha$ is reversibly obtained from this phase at $T=360 \mathrm{~K}(\Delta H \beta \rightarrow \alpha=$ $1.47 \mathrm{~kJ} \mathrm{~mol}^{-1}$ ) and, in this higher temperature phase, the two monomeric units of the unit cell become equivalent [34,37]. However, the precise structural characterization of this phase has not yet been reported.

In order to shed light on the structural changes associated with the $\beta \rightarrow \alpha$ transition, vibrational spectra of these two phases were recorded and fully assigned [38] (phase $\gamma$ was not considered in this study). The assignments were supported by comparison with results obtained by $6-31 \mathrm{G}^{*}$ ab initio molecular orbital calculations carried out for the dimeric structures built by the monomeric units that correspond to the most stable conformers for the isolated molecule situation.

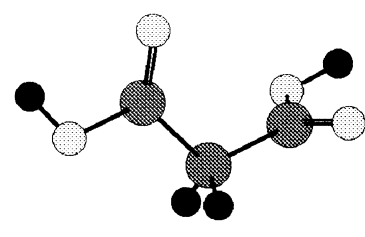

Form I

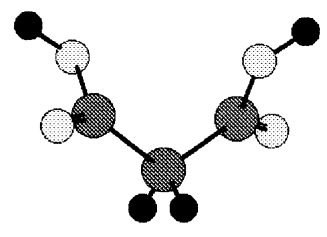

Form II

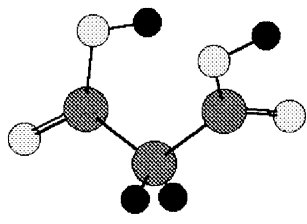

Form III

Fig. 8. Conformers of malonic acid (monomer). 

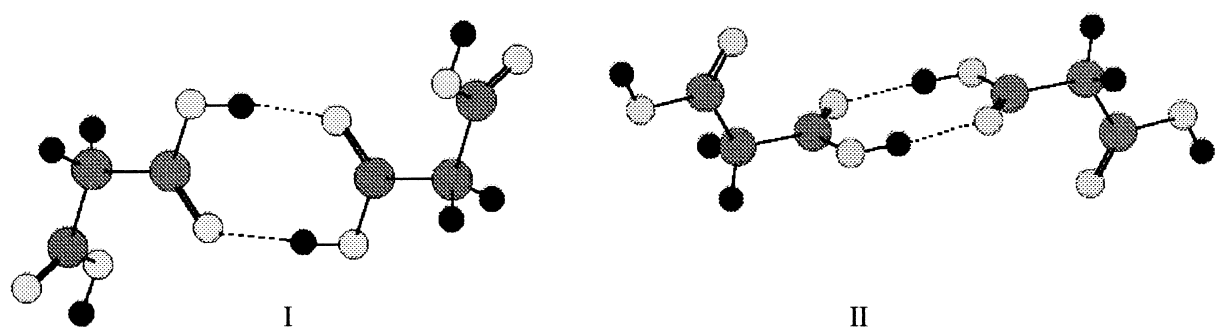

II

Fig. 9. Model dimers used to calculate spectra of crystalline malonic acid (phase $\beta$ ).

A systematic conformational search was undertaken in order to determine the lowest energy conformers of the monomer of malonic acid. Three minima were found in the $6-31 \mathrm{G}^{*}$ potential energy surface (Fig. 8): the most stable form (conformer I) has the two carboxylic groups nearly perpendicular to each other, both of them exhibiting an s-cis structure; the second more stable conformer (form II) has a calculated energy $1.7 \mathrm{~kJ} \mathrm{~mol}^{-1}$ higher than conformer I and has $\mathrm{C}_{2}$ symmetry, showing two equivalent-bysymmetry $s$-cis carboxylic groups. The less stable conformer (form III) has one s-trans carboxylic
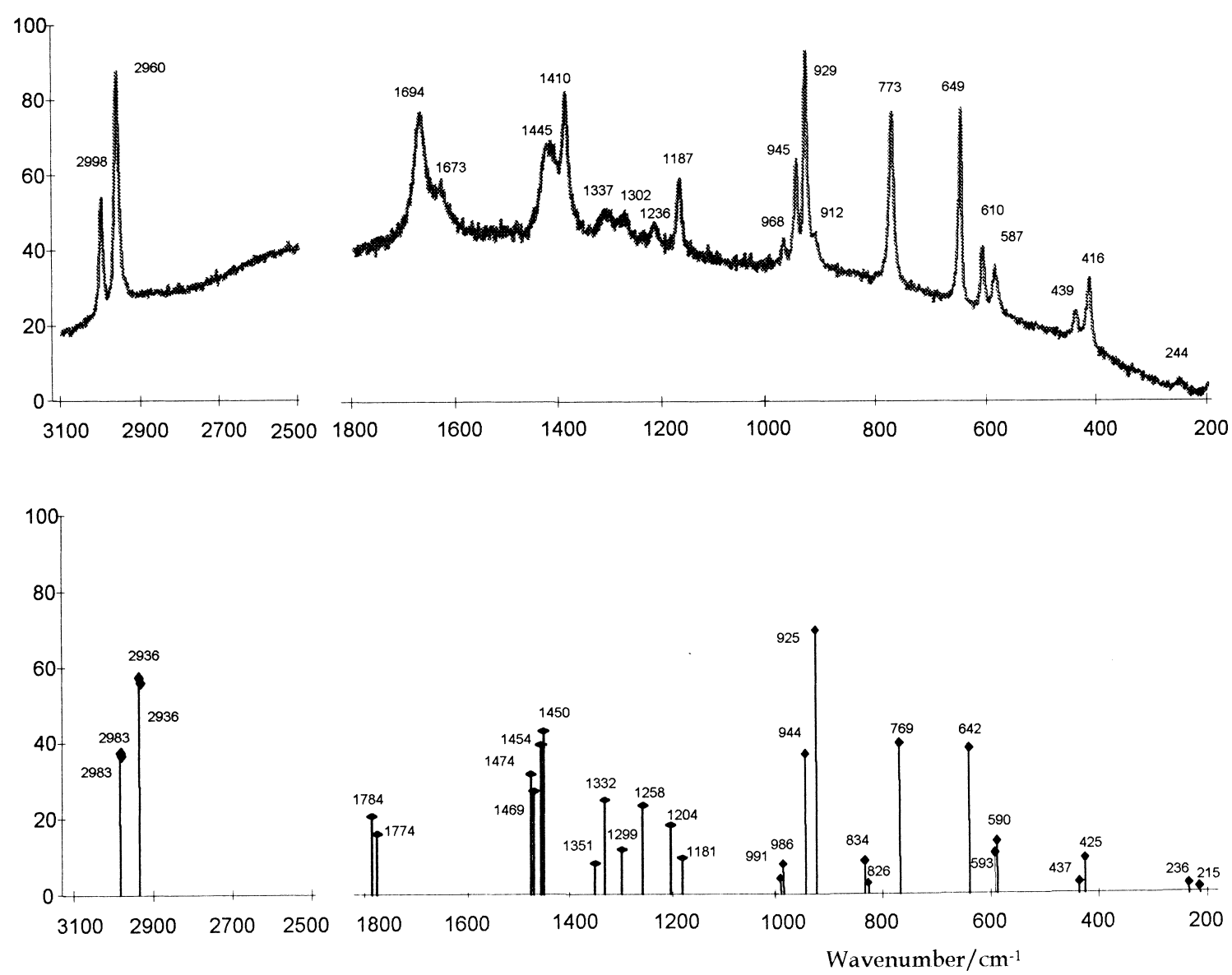

Fig. 10. Experimental and calculated (scaled) Raman spectra of crystalline malonic acid (phase $\beta$ ). 


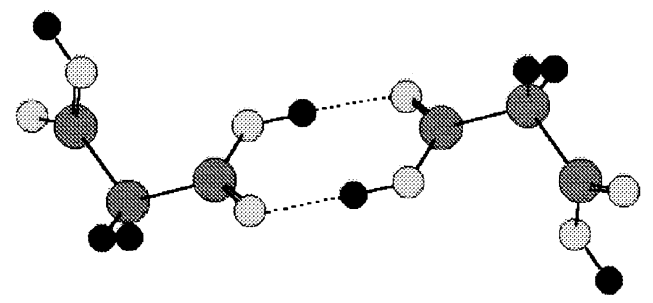

Fig. 11. Model dimer used to calculate spectra of crystalline malonic acid (phase $\alpha$ ).

group and has an energy higher than form I by $22.5 \mathrm{~kJ} \mathrm{~mol}^{-1}$.

It is noteworthy that the monomeric units present in the $\beta$ crystalline phase are similar to form $\mathrm{I}$, the most stable conformer for the isolated molecule of the acid. The ab initio predicted spectra of the crystal (two dimeric models were considered in order to simulate the two non-equivalent carboxylic rings which are present in the crystal; Fig. 9) closely match the observed spectra (in Fig. 10 the calculated and observed Raman spectra, in the $3100-200 \mathrm{~cm}^{-1}$ spectral region, are shown as an example, but the IR spectra show a similar agreement [38]).

To simulate the $\alpha$ crystalline phase, a dimer formed by two monomeric units with the structure of the second more stable conformer for the isolated molecule situation (form II) was submitted to the calculations (Fig. 11). The comparison of the calculated spectra (both Raman and IR) of this dimeric structure with the experimental spectra of phase $\alpha$ unequivocally shows that the model here assumed for this phase is consistent with the experimental data (Raman spectra are shown in Fig. 12, as an example). It is interesting to note that the energetic data for interconversion between the isolated monomers present in the crystalline phases here studied (6$31 \mathrm{G}^{*}$ calculated $\Delta E_{\text {form II }}{ }^{-}$form I $=1.7 \mathrm{~kJ} \mathrm{~mol}^{-1}$ ) are
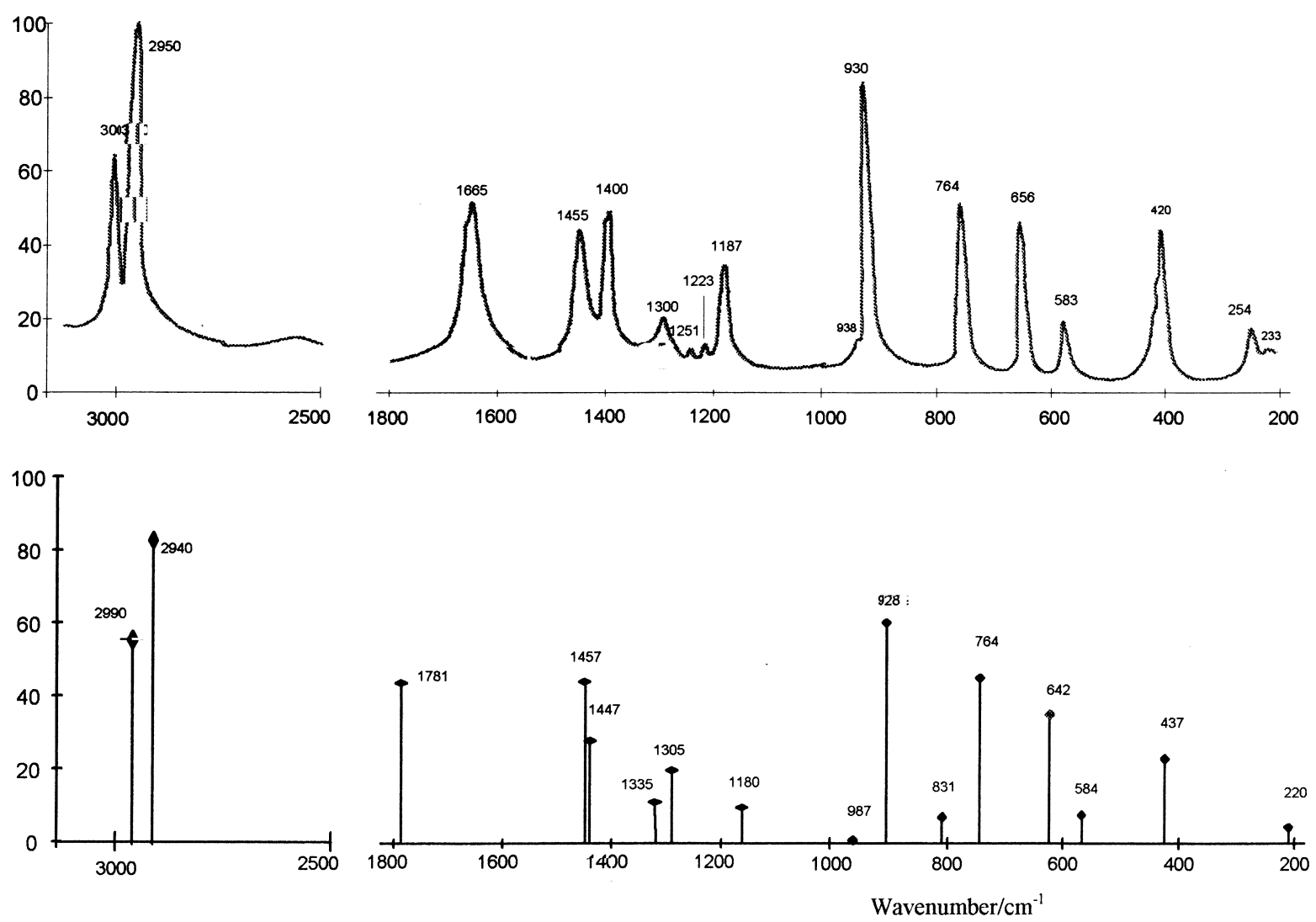

Fig. 12. Experimental and calculated (scaled) Raman spectra of crystalline malonic acid (phase $\alpha$ ). 
of the same order or magnitude of the solid-solid phase transition $\left(\Delta H_{\beta \rightarrow \alpha}=1.47 \mathrm{~kJ} \mathrm{~mol}^{-1}\right)$, thus giving further support to the spectroscopic evidences.

\section{Conclusion}

In this article, the great versatility and power of a concerted approach by low temperature matrix-isolation and solid state spectroscopy, complemented by systematic molecular orbital calculations, to the study of the conformational preferences exhibited by isolated molecules and the effects on these of aggregation, temperature changes and irradiation, is pointed out. Such an approach enables to reach a better understanding of the systems under study in a considerably wide range of experimental conditions. The examples used to illustrate this methodology of study consider a series of molecular systems that are not easily accessible to experiment (e.g., monomeric forms of carboxylic acids) and cover a wide range of applications, going from conformational analysis to aggregation, phase transitions and photochemical reactivity.

\section{Acknowledgements}

This work was held within the PRAXIS XXI (QUI/ $2 / 2.1 / 412 / 94)$ research programme that is also partially funded by FEDER.

\section{References}

[1] R.J.H. Clark, R.E. Hester (Eds.), Time Resolved Spectroscopy, in: Advances in Spectroscopy, Vol. 18, 1989.

[2] M. Bridoux, M. Delhaye, Time resolved and space resolved Raman spectroscopy, in: R.J.H. Clark, R.E. Hester (Eds.), Advances in Infrared and Raman spectroscopy, Vol. 2, Wiley, New York, 1976.

[3] R. Fausto (Ed.), Low Temperature Molecular Spectroscopy, NATO-ASI Series C, 483, Kluwer, Dordrecht, NL, 1996.

[4] A.J. Downs, M. Hawkins, Raman studies of molecules in matrices, in: R.J.H. Clark, R.E. Hester (Eds.), Advances in Infrared and Raman Spectroscopy, Vol. 10, Ch. 1, Wiley, New York, 1983.

[5] J. Nieminen, M. Pettersson, M. Rasanen, J. Phys. Chem. 97 (1983) 10925.

[6] J. Nieminen, Ann. Acad. Sci. Fennic. A254 (1994) 1.
[7] A. Kulbida, R. Fausto, J. Chem. Soc. Faraday Trans. 89 (1993) 4257.

[8] A. Kulbida, A. Nosov, J. Mol. Struc. 265 (1992) 17.

[9] W.J. Hehre, R. Ditchefield, J.A. Pople, J. Chem. Phys. 56 (1972) 2257.

[10] M.J.S. Dewar, E.G. Zoebisch, E.F. Healy, J.J.P. Stewart, J. Am. Chem. Soc. 107 (1985) 3902.

[11] M.J. Frisch, G.W. Trucks, H.B. Schlegel, P.M.W. Gill, B.G. Johson, M.W. Wong, J.B. Foresman, M.A. Robb, M. HeadGordon, E.S. Replogle, R. Gomperts, J.L. Andres, K. Raghavachari, J.S. Binkley, C. Gonzalez, R.L. Martin, D.J. Fox, D.J. Defrees, J. Baker, J.J.P. Stewart, J.A. Pople, GAUSSIAN 92/ DFT (Revision G.2), Gaussian Inc., Pittsburgh PA, 1993.

[12] H.B. Schlegel, Ph.D. Thesis (Queen's University, Kingston, Ontario, Canada), 1975.

[13] M.D.G. Faria, R. Fausto, TRANSFORMER (version 1.0), Departmento de Química, Universidade de Coimbra, Portugal, 1990.

[14] M.D.G. Faria, R. Fausto, BUILD-G and VIBRAT, Departmento de Química, Universidade de Coimbra, Portugal, 1990 (these programs incorporate several routines from programs GMAT and FPERT, H. Fuher, V.B. Kartha, K.G. Kidd, P.J. Krueger, H.H. Mantsch, Natl. Res. Council Can. Bull. 15 (1976) 1.

[15] B.P. van Eijck, A.A.J. Maagdenberg, J. Wanrooy, J. Mol. Struct. 22 (1974) 61.

[16] J.L. Derissen, J.M.J.M. Bijen, J. Mol. Struct. 29 (1975) 153.

[17] R. Fausto, J.J.C. Teixeira-Dias, J. Mol. Struct. 144 (1986) 225.

[18] R. Fausto, L.A.E.B. Carvalho, J.J.C. Teixeira-Dias, J. Mol. Struct. (Theochem.) 207 (1990) 67.

[19] P.J. Tonge, M. Pusztai, A.J. White, C.W. Wharton, P.R. Carey, Biochemistry 29 (1991) 4790.

[20] T. Shimanouchi, Tables of Molecular Vibrational Frequencies, National Standard Reference Data series, National Bureau of Standards, Whashington DC, 1972.

[21] H. Hollenstein, Hs.H. Gunthard, J. Mol. Spectrosc. 84 (1980) 457.

[22] B. Silvi, P. Labarbe, J.P. Perchard, Spectrochim. Acta. A29 (1973) 263.

[23] H. Dubost, L. Abouaf-Marguin, Chem. Phys. Lett. 17 (1972) 269.

[24] H. Dubost, Chem. Phys. 12 (1976) 139.

[25] R.P. Muller, H. Hollenstein, J.R. Huber, J. Mol. Spectrosc. 100 (1983) 95.

[26] A. Kulbida, M.N. Ramos, M. Rasanen, J. Nieminen, O. Schrems, R. Fausto, J. Chem. Soc, Faraday Trans. 91 (1995) 1571.

[27] M.D.G. Faria, J.J.C. Teixeira-Dias, R. Fausto, Vibrat. Spectrosc. 2 (1991) 107.

[28] R. Fausto, Conformational isomerism and photodecomposition of carboxylic compounds studied by matrix isolation infrared spectroscopy, in: R. Fausto (Ed.), Low Temperature Molecular Spectroscopy, NATO-ASI Series, C, 483, Ch. 4, Kluwer, Dordrecht, NL, 1996.

[29] L. Leiserowitz, Acta Cryst. B32 (1976) 775.

[30] S. Block, S.E. Filippakis, G.M.J. Schmidt, J. Chem. Soc. (1967) B233. 
[31] Y. Chatani, Y. Sakate, I. Nitta, Polymer Lett. 1 (1963) 419.

[32] J.R. Barceló, M. Pilar-Jorge, C. Otero, J. Chem. Phys. 28 (1958) 1230.

[33] W. Derbyshire, T.C. Gorvin, D. Warmer, J. Mol. Phys. 17 (1969) 401.

[34] S. Ganguly, J.R. Fernandes, G.R. Desiraju, C.N.R. Rao, Chem. Phys. Lett. 69 (1980) 227.

[35] C.N.R. Rao, S. Ganguly, H.R. Swamy, Croat. Chem. Acta 55 (1982) 207.
[36] J.A. Goedkoop, C.H. MacGillarvry, Acta Cryst. A10 (1957) 125.

[37] R.C. Delaphane, W.I.F. David, R. Ibberson, C.C. Wilson, Chem. Phys. Lett. 201 (1993) 75.

[38] E.M.S. Maçôas, (Caracterização Estrutural e Espectroscópica de Ácidos Carboxílicos: Ácido Oxálico, Ácido Maleico, Ácido Fumárico e Ácido Malónico), Departamento de Química, Universidade de Coimbra, P-3049 Coimbra (Portugal), Internal Report, 1997. 